\title{
AVALIAÇÃO DA QUALIDADE MICROBIOLÓGICA DE EFLUENTES SANITÁRIOS TRATADOS POR SISTEMAS DE LODOS ATIVADOS
}

\author{
Maria Cristina de Almeida Silva ${ }^{1}$, Luiz Olinto Monteggia ${ }^{2}$, Indianara Cataneo ${ }^{3}$
}

\begin{abstract}
Resumo: A maioria das estações construídas para tratamento de efluentes domésticos alcança apenas o nível de tratamento secundário. Desta forma, o efluente sanitário, mesmo que submetido a um processo de tratamento, pode não apresentar qualidade microbiológica satisfatória para ser disposto em corpos receptores. Sendo assim, o objetivo deste trabalho foi avaliar a qualidade microbiológica, através do monitoramento dos indicadores de contaminação coliformes totais e Escherichia coli, de efluentes domésticos tratados por sistema de lodo ativado, durante o período de um ano. Verificou-se maior quantidade das bactérias no verão, período também relacionado ao maior índice pluviométrico. O sistema de lodo ativado apresentou eficiência acima de $98 \%$ na remoção de ambos os organismos avaliados. Contudo, mesmo com a elevada eficiência, verificou-se quantidade considerável de microrganismos no efluente tratado liberado para o meio ambiente. As bactérias E. coli são a causa etiológica de diversas doenças de veiculação hídrica, e por isso esta constatação reforça a preocupação com a saúde pública.
\end{abstract}

Palavras-chave: Efluente sanitário. Bactérias coliformes totais. Escherichia coli. Tratamento de efluentes. Lodo ativado.

\section{MICROBIOLOGICAL QUALITY EVALUATION OF SANITARY WASTEWATER TREATED BY ACTIVATED SLUDGE SYSTEMS}

Abstract: Many wastewater treatment plants for treatment of domestic effluents are built to reach the secondary treatment. The sanitary effluent may not present satisfactory microbiological quality to be disposed in water bodies, even if it was submitted to a treatment process. Therefore, the objective of this

1 Engenheira de Bioprocessos e Biotecnologia. Mestre e Doutora em Recursos Hídricos e Saneamento Ambiental pelo Instituto de Pesquisa Hidráulicas da UFRGS - Porto Alegre (RS), Brasil. Professora Univates - Lajeado (RS), Brasil.

2 Engenheiro Mecânico e Civil. Mestre em Recursos Hídricos e Saneamento Ambiental pelo Instituto de Pesquisa Hidráulicas da UFRGS; Doutor em Engenharia Sanitária pela University of Newcastle (UK); Professor Titular no Departamento de Obras Hidráulicas e pesquisador do Programa de PósGraduação em Recursos Hídricos e Saneamento Ambiental do Instituto de Pesquisa Hidráulicas da UFRGS - Porto Alegre (RS), Brasil.

3 Engenheira Ambiental, pela Univates. Trabalha na Bremil Indústria de Produtos Alimentícios LTDA. 
work was to evaluate the microbiological quality of domestic effluents treated by activated sludge system, during the period of one year, by monitoring the contamination indicators total coliform and Escherichia coli. There was a higher amount of bacteria in the summer, when it was verified also the higher rainfall index. The activated sludge system presented efficiency above $98 \%$ in the removal of both evaluated organisms. However, a considerable amount of microorganisms was found in the treated effluent released into the environment, even at high efficiency. The E. coli bacteria are the etiological cause of several waterborne diseases, and the of this work results reinforces the public health concern.

Keywords: Sanitary wastewater, total coliform bacteria, Escherichia coli, wastewater treatment, activated sludge.

\section{INTRODUÇÃO}

A água, após ser utilizada nos mais diversos fins, se transforma em efluente. De acordo com a Norma Brasileira (NBR) 9648/1986, que fixa as condições exigíveis no estudo de concepção de sistemas de esgoto sanitário do tipo separador, efluente doméstico é o despejo líquido resultante do uso da água para higiene e necessidades fisiológicas humanas. Já o efluente sanitário é definido como o despejo líquido constituído de efluente doméstico e industrial, água de infiltração e a contribuição pluvial parasitária (ABNT, 1986).

A falta de saneamento é um dos maiores problemas do Brasil, mesmo que haja no país a consciência de que o tratamento e o destino final do esgoto têm relação direta com o meio ambiente e a qualidade das águas e seus benefícios (MMA, 2009). Ressalta-se a problemática relacionada aos baixos índices ou ao nenhum tratamento dos efluentes sanitários. Sendo assim, os mesmos são lançados em rios, lagos e represas, contribuindo para o baixo índice de qualidade da água, que ameaça a saúde da população e que compromete a preservação do meio ambiente (IBGE, 2015). Como impacto resultante do lançamento de efluentes não tratados, ou não tratados de forma satisfatória, ressaltase o surgimento de várias doenças de veiculação hídrica (MACHADO et al., 2015).

Conforme Sistema Nacional de Informaçôes sobre Saneamento (SNIS, 2016), apenas $42,67 \%$ dos esgotos domésticos produzidos no Brasil são tratados, verificando-se grande variabilidade deste índice entre regiões brasileiras. Na região norte, este índice é $16,42 \%$, contra 50,22\% da região Centro-oeste. Contudo, o efluente sanitário somente terá características adequadas para ser lançado em corpo receptor conforme o nível de tratamento a que for submetido.

Os processos de tratamento são empregados visando a remoção ou a transformação de substâncias indesejáveis (JORDÃO; PESSOA, 2005). Os mesmos compreendem uma série de operações unitárias, com eficiências distintas (MMA, 2009), e podem ser classificados em níveis: preliminar, primário, secundário e terciário.

O tratamento preliminar via a remoção de sólidos grosseiros e areia presentes no efluente, por ação física, evitando o acúmulo de material inerte e abrasivo nas tubulações e das demais unidades das Estações de Tratamento de Efluentes (ETE). O tratamento 
primário, ou físico-químico, envolve unidades de tratamento que adotam decantadores primários ou flotadores, que promovem a remoção em que através da sedimentação ou coagulação e floculação das partículas existentes (JORDÃO; PESSOA, 2005).

Já o tratamento secundário, por sua vez, destina-se à degradação biológica de compostos carbonáceos, nos chamados reatores biológicos. Esses reatores são normalmente constituídos por tanques com grande quantidade de microrganismos, podendo ser aeróbios (presença de oxigênio) ou anaeróbios (ausência de oxigênio). Os sistemas de lodo ativado são bastante empregados, pois promovem ótima eficiência para remoção de carga orgânica (BONIFASSIO, 2013).

Este sistema é constituído de reator biológico aerado, decantação e recirculação de lodo. Neste tratamento, a biomassa existente degrada as substâncias orgânicas presentes no efluente e as transformam em água, energia, dióxido de carbono e material celular para o crescimento bacteriano. Os decantadores são incumbidos de separar os sólidos em suspensão, presentes no tanque de aeração. A recirculação da biomassa retida no decantador para o reator biológico aumenta a eficiência deste processo (FELIPPE, 2009; BONIFASSIO, 2013).

Por fim, o tratamento terciário se destina à remoção de substâncias recalcitrantes, nutrientes e organismos patogênicos. Dentre os processos, destaca-se a desinfecção, que tem como objetivo a redução considerável no número de patogênicos, sendo essencial para assegurar a não contaminação dos corpos hídricos (METCALF; EDDY, 2015).

Conforme Machado (2014) e MMA (2009), a maioria das estações construídas para tratamento de efluentes domésticos alcança apenas o nível de tratamento secundário. Nesta escolha, é considerado apenas a redução do nível de poluição por matéria orgânica, pois após ser submetido a esta etapa, o efluente pode, na maioria dos casos, ser lançado diretamente no corpo receptor, mesmo sem a desinfecção, a nível terciário, ter sido realizada. Desta forma, é importante frisar que, mesmo com a realização do tratamento, pode não ser possível assegurar que o efluente sanitário tenha qualidade microbiológica satisfatória para ser disposto em corpos receptores.

Sendo assim, este trabalho teve como objetivo avaliar a qualidade microbiológica do efluente sanitário tratado por uma ETE, a nível secundário. Para isso, os parâmetros coliformes totais e Escherichia coli foram monitorados durante um ano.

\section{METODOLOGIA}

O estudo foi conduzido com amostras de efluente sanitário coletadas em uma Estação de Tratamento de Efluentes, localizada no município de Porto Alegre. Os tratamentos realizados nesta ETE são o preliminar, constituído de gradeamento e caixa de areia, e o secundário, pelo sistema de lodo ativado. O lodo resultante do tratamento preliminar é encaminhado a aterro sanitário, e do secundário, é digerido para posteriormente ser incorporado em compostagem. 
Neste trabalho, foram coletadas amostras do efluente bruto à ETE, bem como do efluente tratado, proveniente do processo de lodo ativado, conforme a Figura 1.

Figura 1 - Fluxograma geral da ETE

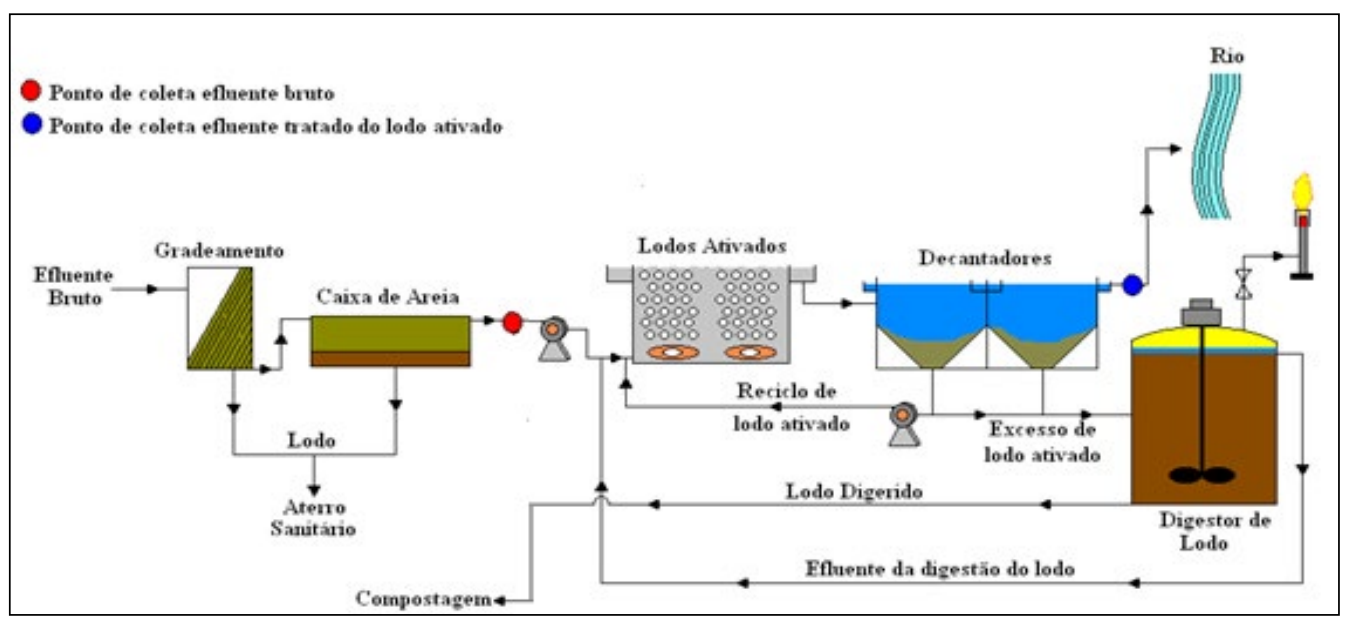

Fonte: Silva et al (2015).

As amostras foram colhidas durante o período de junho de 2006 a junho de 2007. A coleta de amostra foi realizada semanalmente, no turno da manhã. Foram coletados cerca de $1 \mathrm{~L}$ de cada amostra, e enviados ao Laboratório de Saneamento do Instituto de Pesquisas Hidráulicas da Universidade Federal do Rio Grande do Sul.

Foram analisadas 66 amostras coletadas durante o período de estudo: 33 amostras de efluente bruto e 33 de efluente de lodo ativado, para determinação da quantidade de coliformes totais e Escherichia coli.

\section{Identificação e quantificação de coliformes totais e Escherichia coli nas amostras}

A quantificação de Escherichia coli e coliformes totais foi realizada conforme metodologia descrita em Standard Methods for the Examination of Wastewater (APHA, 2005).

A determinação de coliformes totais e de Escherichia coli foi realizada a partir da utilização de substrato cromogênico-fluorogênico-hidrolizável, empregando $100 \mathrm{~mL}$ das duas amostras, oriundas dos diferentes pontos de coleta. Em algumas situações foi necessária a realização de diluição seriada para a quantificação, de $10^{-3}$ a $10^{-6}$. Aos efluentes, foram misturados o meio de cultura Colilert ${ }^{\circledR}$ (IDEXX), e após homogeneização, toda a mistura foi transferida para uma cartela Quantitray, e selada em seladora específica. Em seguida, as cartelas foram incubadas a $35^{\circ} \mathrm{C}$ coliformes 
totais por 24 horas. Transcorrido este tempo, a quantificação dos coliformes totais foi realizada a partir da determinação das células da cartela Quantitray que apresentam coloração amarela.

Já a quantificação de $E$. coli foi realizada a partir da identificação do número de células da cartela que apresentaram fluorescência, quando exposta à radiação ultravioleta. Posteriormente, consultou-se uma tabela específica, que determina o número mais provável destes organismos.

\section{RESULTADOS E DISCUSSÕES}

Conforme Silva (1997), o grupo de coliformes totais inclui as bactérias na forma de bastonetes Gram-negativos, não esporogênicos, aeróbios ou aeróbios facultativos, capazes de fermentar a lactose com produção de gás, em 24 a 48 horas a $35^{\circ} \mathrm{C}$. Este grupo apresenta bactérias oriundas do trato intestinal de humanos e outros animais de sangue quente.

Já os coliformes termotolerantes são um subgrupo das bactérias do grupo coliforme que fermentam a lactose a $44,5 \pm 0,2^{\circ} \mathrm{C}$ em 24 horas, tendo como principal representante a Escherichia coli, de origem exclusivamente fecal (CONSEMA, 2006).

A presença de bactérias patogênicas em águas pode acarretar problemas indesejáveis, principalmente relacionadas à saúde pública. Os microrganismos de origem entérica, animal ou humana, podem causar doenças de veiculação hídrica, sendo, em sua maioria, transmitidos pela rota fecaloral, ou seja, são excretados nas fezes de indivíduos infectados e ingeridos na forma de água ou alimento contaminado (AMARAL et al., 2003, SILVA et al., 2015). As bactérias coliformes são os microrganismos mais utilizados como referência para indicar e medir a grandeza da contaminação

O uso de E. coli para indicar contaminação sanitária mostra-se mais significativo que o uso da bactéria coliforme total, pois as primeiras são restritas ao trato intestinal de animais de sangue quente. Sendo assim, a determinação da concentração dos coliformes pode indicar a existência de microrganismos patogênicos, responsáveis pela transmissão de doenças de veiculação hídrica, tais como febre tifoide e paratifoide, desinteria bacilar e cólera (ORTEGA et al., 2009; LECT, 2017).

No presente estudo, o efluente bruto apresentou uma elevada quantidade de microrganismos durante todo o período analisado. Observou-se decréscimo na quantidade de microrganismos presentes no tratamento de lodo ativado analisado, conforme pode ser visualizado na Figura 2. Os valores das médias encontradas em

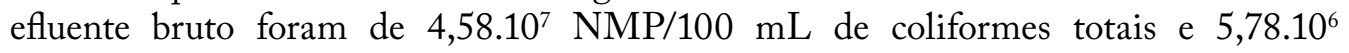
$\mathrm{NMP} / 100 \mathrm{~mL}$ de E. coli. No efluente final, do processo de lodo ativado, houve o decaimento microbiano, com 4,67.10 $\mathrm{NMP} / 100 \mathrm{~mL}$ de coliformes totais, 8,65.104 $\mathrm{NMP} / 100 \mathrm{~mL}$ de $E$. coli. Sendo assim, O processo de tratamento apresentou valores de eficácia de remoção de cerca de $98,9 \%$ de coliformes totais, $98,5 \%$ de $E$. coli. 
Figura 2 - Média da quantidade de microrganismos encontrados no efluente bruto e tratado da ETE em estudo, durante o período analisado

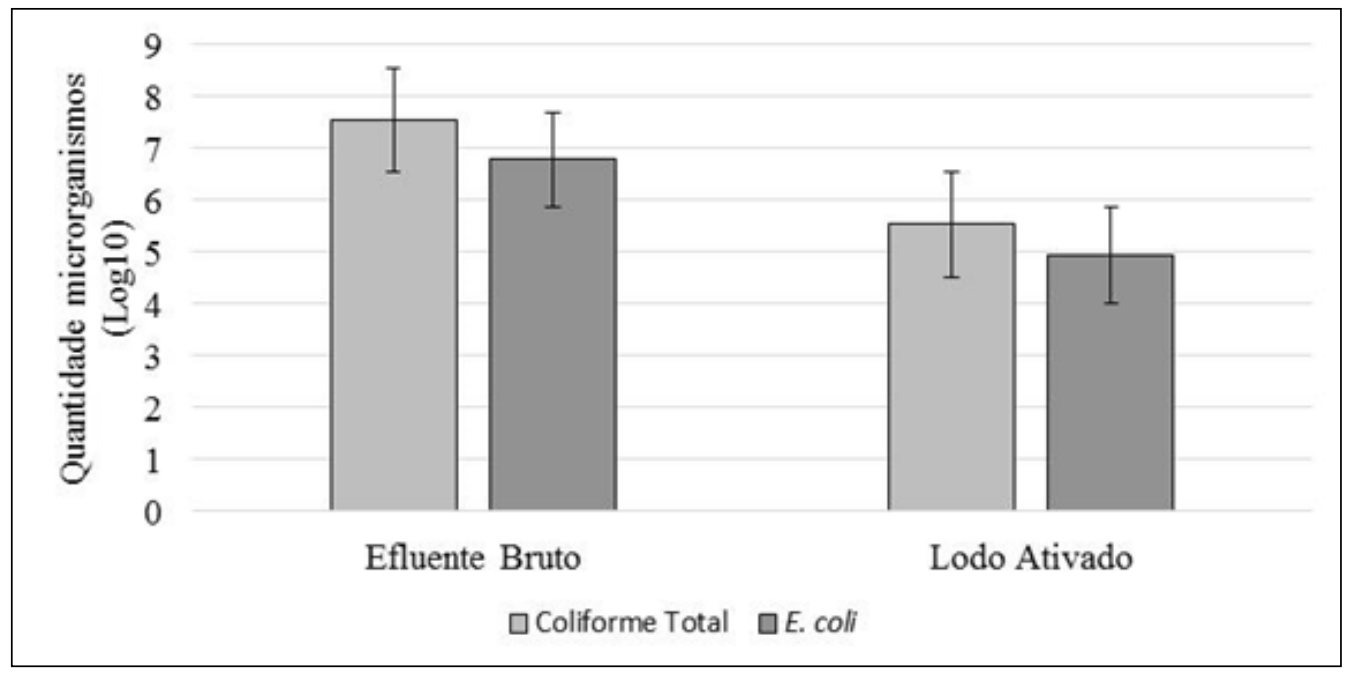

Fonte: dos autores.

De acordo com Von Sperling (2005), espera-se eficiência de remoção de 90\% de microrganismos em processos de lodo ativado. No presente estudo, foram obtidos valores acima de $98 \%$ referentes à remoção de microrganismos neste sistema, ou seja, mais satisfatório do que descrito na literatura.

A Resolução CONSEMA no 128/2006 estabelece padrões de lançamento de efluentes, tanto domésticos como industriais, no estado do Rio Grande do Sul (BRASIL, 2006). A mesma determina que a quantidade de Escherichia coli em corpos hídricos não ultrapasse $10^{3} \mathrm{NMP} / 100 \mathrm{~mL}$. Desta forma, verifica-se que o efluente final da ETE lançou no período estudado cerca de uma unidade logarítmica a mais do que o estabelecido.

As Figuras 3 e 4 abaixo mostram a quantidade de microrganismos presentes no efluente bruto e tratado por lodo ativado, respectivamente, bem como suas respectivas linhas de tendência, durante o período de análise de 1 ano. Ressalta-se que em todo o período de análise foram constatadas a presença dos microrganismos, em ambos os efluentes avaliados. No efluente bruto, a menor concentração encontrada foi de cerca de 5 unidades logarítmicas de $E$. coli, e efluente tratado, aproximadamente 3 unidades logarítmicas, também deste organismo. Verifica-se também que há a tendência da presença de maiores quantidades de coliformes totais e $E$. coli durante o verão, sendo mais pronunciado no efluente tratado. 
Figura 3 - Qualidade de microrganismos, coliformes totais e $E$. coli, no efluente bruto durante o período de análise

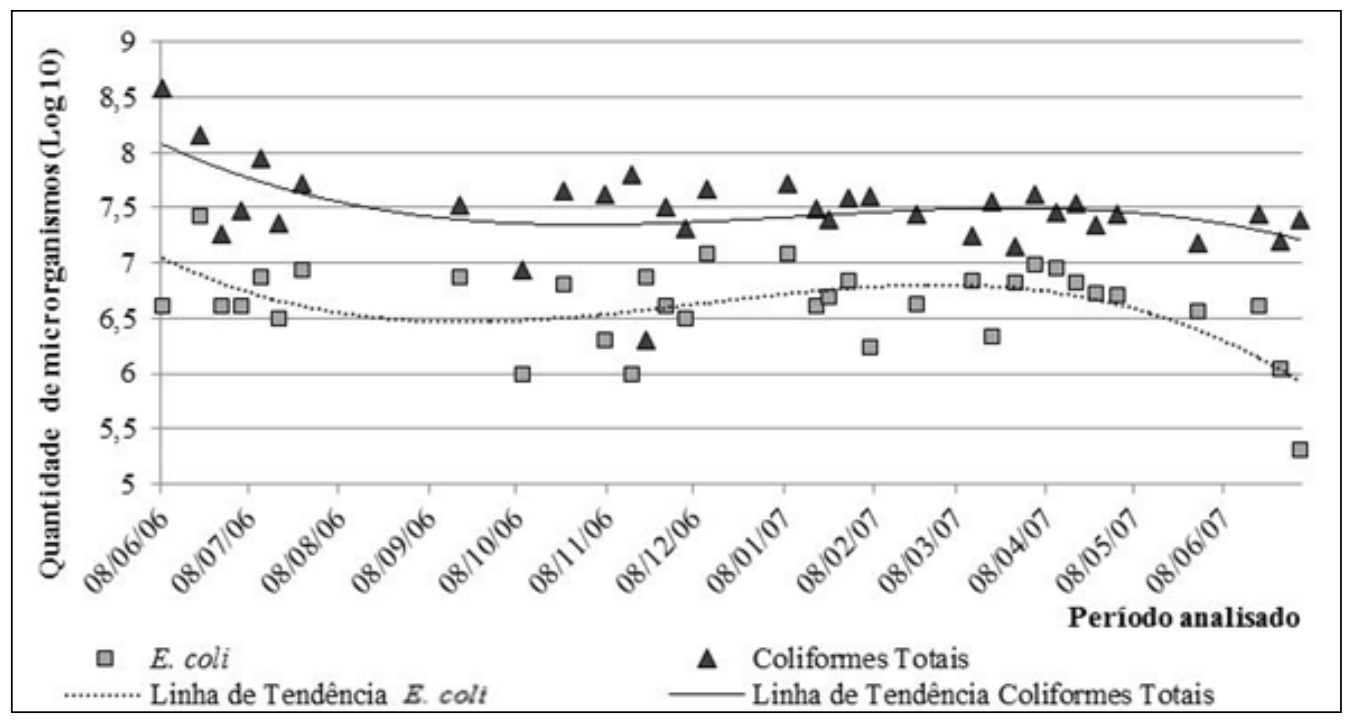

Fonte: dos autores.

Figura 4 - Quantidade de E. coli e coliformes totais encontrados em efluente tratado, por processo de lodo ativado, durante o período de estudo

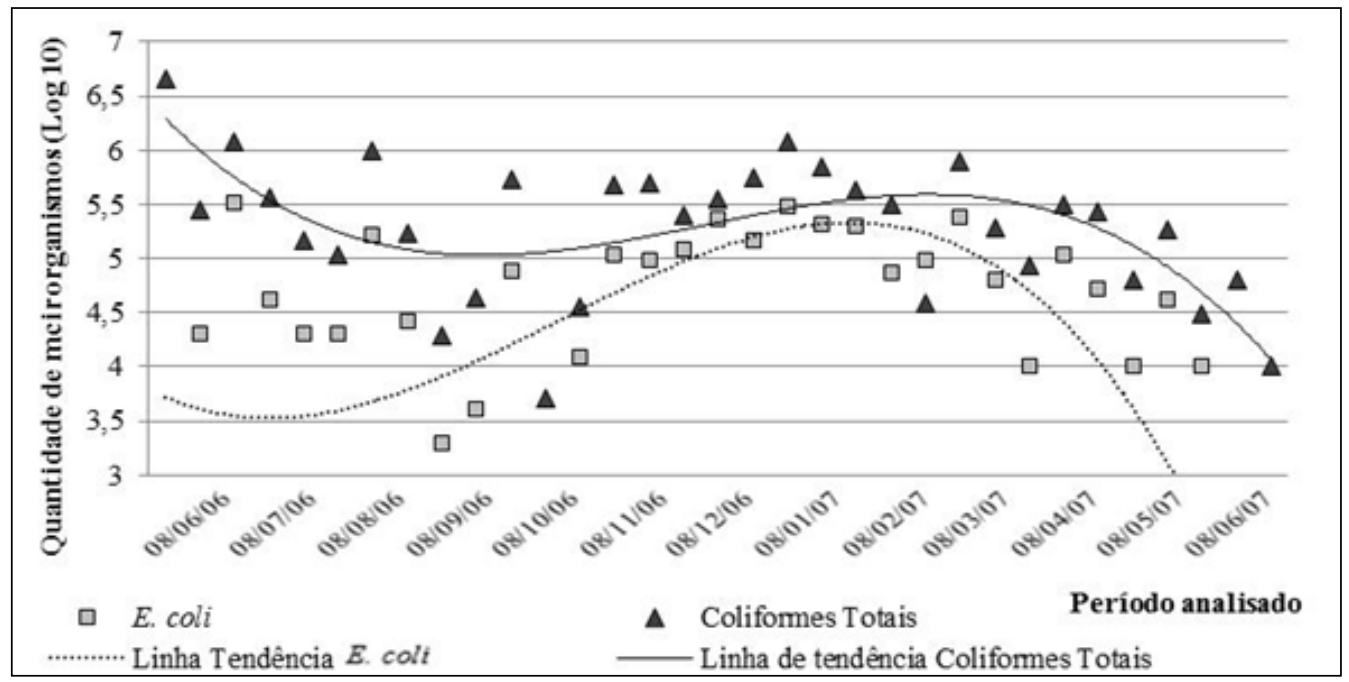

Fonte: dos autores.

No período de realização deste estudo (junho de 2006 a junho de 2007), o verão e o outono se caracterizaram por apresentar alto índice pluviométrico, enquanto que o baixo índice de chuvas foi observado no inverno e na primavera. De acordo com 
Espinoza et al. (2009), as bactérias coliformes não apresentam tendência relacionada ao clima. Contudo, segundo Emiliani e Gonzalez (1998) e Lemos, Ferreira Neto e Dias (2010), a quantidade de coliformes termotolerantes ou $E$. coli pode ser relacionada com os maiores níveis pluviométricos, que apresentam maior contribuição de contaminação de origem difusa.

Para ser considerado ideal, um processo de tratamento de efluentes deve apresentar baixo custo operacional e oferecer efluente com boa qualidade higiênico-sanitária. De uma forma geral, o tratamento por lodo ativado demonstra elevada eficiência de remoção de matéria carbonácea. Contudo, essa eficiência é aliada a elevados custos operacionais. Além do excesso de lodo, que necessita de tratamento complementar para sua disposição final ou reuso, o tratamento por lodo ativado também requer custos de implantação e operação, devido ao seu alto consumo energético (VON SPERLING, 2005). Mesmo apresentando elevado decaimento microbiano neste estudo, o efluente ainda apresentou considerável quantidade de microrganismos (em média quatro unidades logarítmicas), não atendendo ao requisito proposto pela Resolução CONSEMA no 128 , quando relacionado a $E$. coli.

Este resultado ressalta que, mesmo apresentando eficiência acima de 98\% para a remoção e/ou inativação de microrganismos, o efluente da ETE não apresentou qualidade microbiológica adequada para ser disposta em corpos hídricos, durante o período de estudo. Sabe-se que as bactérias $E$. coli são a causa etiológica de diversas doenças de veiculação hídrica, e por isso esta constatação reforça a preocupação com a saúde pública.

Sendo assim, verificou-se que mesmo após ser submetido a tratamento, o efluente dificilmente estará isento de microrganismos patogênicos, o que pode acarretar problemas relacionados à saúde pública. Com os resultados obtidos, destaca-se a importância da inclusão de uma etapa adicional de tratamento na ETE em estudo. A desinfecção, a nível terciário, pode ser definida como responsável pela redução das densidades de microrganismos (METCALF; EDDY, 2015), até os limites estabelecidos pela legislação, seja para destinação final, seja para diferentes tipos de reuso, como por exemplo irrigação e/ou balneabilidade. Este tratamento adicional removeria os microrganismos, assegurando a qualidade microbiológica do efluente.

\section{CONCLUSÕES}

- Quantidades consideráveis de bactérias coliformes, totais e E. coli, foram detectadas em todas as amostras analisadas, em todas as estações do ano, inclusive no efluente final da ETE;

- Verificou-se tendência de maiores concentrações de microrganismos em ambos os efluentes analisados no verão, podendo ser associados a períodos com maior índice pluviométrico; 
- Foi verificado decaimento microbiano no tratamento de lodo ativado, contudo não em quantidade suficiente para assegurar a qualidade microbiológica do efluente.

\section{REFERÊNCIAS}

AMARAL, L.A.; NADER F.A.; ROSSI JUNIOR, O.D..; FERREIRA, F.L.A.; BARROS, L.S.S. (2003) Água de consumo humano como fator de risco à saúde em propriedades rurais. Revista de Saúde Pública, v. 37, n. 4, p. 510514.

APHA - AMERICAN PUBLIC HEALTH ASSOCIATHION. Standard methods for the examination of wastewater. $20^{\text {th }}$ ed. New York, USA: APHA, 2005. $1220 \mathrm{p}$.

ABNT - ASSOCIAÇÃO BRASILEIRA DE NORMAS TÉCNICAS (1986). Norma NBR 9648/1986 - Estudo de concepção de sistemas de esgoto sanitário - Procedimento. Associação Brasileira de Normas Técnicas, Rio de Janeiro, BR.

BONIFASSIO, F. E. (2013). Implantação de um sistema de gestão ambiental nas Estações de Tratamento de Esgoto de Pindamonhangaba. Monografia apresentada à Escola de Engenharia de Lorena da Universidade de São Paulo, como requisito para a conclusão de graduação no curso de Engenharia Industrial Química. Lorena.

CONSEMA - CONSELHO ESTADUAL DO MEIO AMBIENTE. Resolução n. 128, de 7 de dezembro de 2006. Dispõe sobre a fixação de Padrões de Emissão de Efluentes Líquidos para fontes de emissão que lancem seus efluentes em águas superficiais no Estado do Rio Grande do Sul. 9 p. Disponível em: <http://www.sema.rs.gov.br/conteudo.asp?cod_ menu=216\&cod_conteudo=7206>. Acesso em: 19 março de 2016.

EMILIANI, F.; GONZÁLES, S.M.P. (1998). Bacteriological quality of Bendetti Lake (Santo Tome, Santa Fé Province, Argentina) and associated enviromental variables. Revista Argentina de Microbiologia, v. 30, n. 1, p. 3038.

ESPINOZA, A.C.; ARIAS, C.F.; SÁNCHEZCOLÓN, S.; MAZARIHIRIART, M. (2009) Comparative study of enteric viruses, coliphages and indicator bacteria for evaluating water quality in a tropical highaltitude system. Environmental Health, v. 8, p. 49.

FELIPPE, S. W. (2009). Caracterização e tratabilidade do efluente líquido da Indústria de Laticínios Fortuna LTDA, Rio Fortuna/SC. Trabalho de Conclusão de Curso Engenheira Ambiental. Universidade do Extremo Sul Catarinense, UNESC. Criciúma, junho 2009.

IBGE - INSTITUTO BRASILEIRO DE GEOGRAFIA E ESTATÍTICA (2015). Indicadores de desenvolvimento sustentável: Brasil: 2015, 351p

JORDÃO, E. P.; PESSOA, C.A. (2005). Tratamento de esgoto doméstico. ABES. Rio de Janeiro, Brasil, $932 \mathrm{p}$.

LECT - LABORATÓRIO DE ENSINO DE CIÊNCIAS E TECNOLOGIA, Universidade de São Paulo (USP). Disponível em http://lect.futuro.usp.br/site/ecologia/ quadroteorico/c coliformes.htm, acesso em 8 de junho de 2017. 
LEMOS, M.; FERREIRA NETO, M.; DIAS, N.S. (2010) Sazonalidade e variabilidade espacial da qualidade da água na Lagoa do Apodi, RN. Revista Brasileira de Engenharia Agrícola e Ambiental, v. 14, n. 2, p. 155164.

MACHADO, G. B (2014). Processos de tratamento de esgoto sanitário. Portal resíduos sólidos. Disponível em: <http://www.portalresiduossolidos.com/processos-de-tratamento-deesgoto-sanitario/>. Acesso em 25 de maio de 2017.

MACHADO, J. R. M.; UCKER, F. E.; JUNIOR, M. G. S.; ALONSO, R. R. P. (2016) Situação do Saneamento Básico no bairro Vila Mutirão na cidade de Goiânia (GO). Revista Eletrônica de Educação da Faculdade Araguaia, v. 8, n. 8, p. 104-113.

METCALF, L.; EDDY, H. P. (2015). Tratamento de efluentes e recuperação de recursos. 5a ed., McGraw Hill Brasil, 2008 p.

MMA - MINISTÉRIO DO MEIO AMBIENTE (2009). Programa Nacional de capacitação de gestores ambientais: Módulo específico licenciamento ambiental de estações de tratamento de esgoto e aterros sanitários, $67 \mathrm{p}$.

ORTEGA, C.; SOLOGABRIELE, H.M.; ABDELZAHER, A.; WRIGHT, M.; DENG, Y. (2009) Correlations between microbial indicators, pathogens, and environmental factors in a subtropical estuary. Marine Pollution Bulletin, v. 58, n. 9, p. 13741381.

SILVA, M. C. A.; MONTEGGIA, L. O.; MIRANDA, L. A. S.; THEWES, M. R. (2015). Avaliação da viabilidade de utilização de colifagos como indicadores de poluição fecal: suas relações com parâmetros físicos e químicos e indicadores bacterianos. Engenharia Sanitária e Ambiental, v. 20, n. 4, p. 645-652.

SILVA, N. (1997). Manual de métodos de análise microbiológica de alimentos. Livraria Varela, p 31 .

SNIS - SISTEMA NACIONAL DE INFORMAÇÕES SOBRE SANEAMENTO. Ministério das Cidades - Secretaria Nacional de Saneamento Ambiental. Disponível em: <http://app.cidades.gov.br/snisweb/src/Sistema/index>. Acesso em 25 de maio de 2017.

VON SPERLING, M. Introdução à qualidade das águas e ao tratamento de esgotos. 3. ed. Belo Horizonte, MG: Departamento de Engenharia Sanitária e Ambiental - Universidade Federal de Minas Gerais, 2005. 452 p. 